\title{
Incidência de insetos fitófagos e de predadores no milho e no feijão cultivados em sistema exclusivo e consorciado ${ }^{1}$
}

\author{
Insect phitophagous and predators incidence on maize and bean \\ cultivated in exclusive and intercropped systems
}

\author{
Cristina Schetino Bastos ${ }^{1}$ João Carlos Cardoso Galvão ${ }^{2}$ Marcelo \\ Coutinho Picanço ${ }^{3}$ Paulo Roberto Cecon ${ }^{4}$ Paulo Roberto Gomes Pereira ${ }^{2}$
}

\section{RESUMO}

Este trabalho foi conduzido em Coimbra, $M G$, no ano agrícola 1996/97 e objetivou avaliar a ocorrência de insetos fitófagos e de predadores no milho e no feijoeiro cultivados em sistema exclusivo e em policultivo. Foi realizado um cultivo de milho (25/10/1996 a 24/03/1997) e dois cultivos de feijão[o primeiro de 25/10/1996 a 20/01/1997 (cultivo "das águas”) e o segundo de 25/03/1997 a 21/07/1997 (cultivo "da seca")]. Realizaram-se contagens diretas das populações de insetos fitófagos e de predadores nas culturas. Menores densidades populacionais de herbivoros considerados preferenciais da cultura do milho [Dalbulus maidis (Delong \& Wolcott) (Homoptera: Cicadellidae) e Spodoptera frugiperda (Smith) (Lepidoptera: Noctuidae)] e do feijoeiro [Diabrotica speciosa (Germ.), Cerotoma arcuata (Oliv.) (Coleoptera: Chrysomelidae) e Empoasca kraemeri (Ross \& Moore) (Homoptera: Cicadellidae)] estiveram associadas ao cultivo consorciado. As densidades de herbivoros generalistas como Thrips tabaci Lind. (Thysanoptera: Thripidae) e Pseudoplusia includens (Walk.) (Lepidoptera: Noctuidae) foram maiores no feijoeiro consorciado com o milho. No cultivo "das águas", o total de insetos fitófagos foi maior no feijoeiro consorciado com o milho do que no feijoeiro cultivado exclusivamente, sendo que o inverso ocorreu no cultivo "da seca". Os predadores Anthicus sp. (Coleoptera: Anthicidae) e Hymenoptera: Formicidae foram mais abundantes no milho e no feijoeiro cultivados exclusivamente do que as culturas foram consorciadas.

Palavras-chave: Insecta, Zea mays, Phaseolus vulgaris, herbivoros, inimigos naturais.

\section{ABSTRACT}

This work was carried out in Coimbra, MG,Brazil, during the agricultural year of 1996/97 and it had the objective of evaluating the phytophagous insects and predators occurrence in maize and bean cultivated in exclusive and policultive systems. One cultivation of maize (from 10/25/ 1996 to 03/24/1997) and two cultivation of bean were conducted [the first one from 10/25/1996 to 01/20/1997 (rainy period cultivation) and the second one from 03/25/1997 a 07/21/1997 (drought period cultivation)]. The population of phytophagous insects and predators incident in the cultures were counted directly. Lower herbivores population density, which attacks preferentially maize [Dalbulus maidis (Delong \& Wolcott) (Homoptera: Cicadellidae) and Spodoptera frugiperda (Smith) (Lepidoptera: Noctuidae)] and bean [Diabrotica speciosa (Germ.), Cerotoma arcuata (Oliv.) (Coleoptera: Chrysomelidae) and Empoasca kraemeri (Ross \& Moore) (Homoptera: Cicadellidae)] were associated to the intercropped system. The generalists-insect densities as Thrips tabaci Lind. (Thysanoptera: Thripidae) and Pseudoplusia includens (Walk.) (Lepidoptera: Noctuidae) were higher in the bean intercropped with maize. The phytophagous-insect total number was higher in the bean intercropped with maize in the rainy period cultivation than in the bean cultivated exclusively. The opposite happened in the drought period cultivation. The predators Anthicus sp. (Coleoptera: Anthicidae) and Hymenoptera: Formicidae were more abundant in the maize and bean cultivated exclusively than when the cultures were cultivated intercropped.

\footnotetext{
${ }^{1}$ Engenheiro Agrônomo, Pesquisador, Embrapa Algodão, Doutor do programa de pós-graduação em Fitotecnia, Universidade Federal de Viçosa (UFV).

${ }^{2}$ Engenheiro Agrônomo, Professor Adjunto, Doutor., Departamento de Fitotecnia, UFV.

${ }^{3}$ Engenheiro Agrônomo, Professor Adjunto, Doutor, Departamento de Biologia Animal, UFV, 36571-000 Viçosa, MG. E-mail: picanco@mail.ufv.br. Autor para correspondência.

${ }^{4}$ Engenheiro Agrônomo, Professor Adjunto, Doutor, Departamento de Informática, UFV.
} 
Key words: Insecta, Zea mays, Phaseolus vulgaris, herbivores, natural enemies.

\section{INTRODUÇÃO}

O cultivo consorciado envolve o crescimento simultâneo de duas ou mais culturas na mesma área. Este sistema de cultivo é largamente empregado em países em desenvolvimento (KAREL, 1993). No caso de pequenos agricultores cujas propriedades localizam-se geralmente em regiões montanhosas, o objetivo seria extrair o máximo dessas áreas e, para tal, a produção em consórcio é essencial, já que implica uso mais efetivo da terra aliado à diversidade de produção (VIEIRA, 1984). Entre as vantagens do consórcio, a mais citada e documentada é a redução do ataque de pragas em policultivos, já que insetos herbívoros geralmente alcançam maiores densidades populacionais em monocultivo que em estandes multiespecíficos de plantas hospedeiras (VANDERMEER, 1989).

Em face da reduzida capitalização dos pequenos agricultores, a menor demanda para o controle de pragas pode contribuir para redução do custo final da produção, já que inseticidas e adubos constituem alta porcentagem do custo de produção. Outro aspecto relevante é que a redução no uso de inseticidas permite maior sobrevivência de inimigos naturais e estes podem manter as pragas em baixos níveis populacionais (QUINDERÉ \& SANTOS, 1986).

Trabalho desenvolvido por KAREL (1993) mostrou menor incidência de larvas de Heliothis armigera (Hub.) (Lepidoptera: Noctuidae) no feijão cultivado consorciado com o milho que no cultivado exclusivamente. CASTRO et al. (1994) observaram que menores densidades populacionais de Spodoptera frugiperda (Smith) (Lepidoptera: Noctuidae) foram associadas ao cultivo intercalado de milho e sorgo quando o caupi foi inserido no sistema. ROMERO et al. (1994) verificaram que a introdução de leguminosas no sistema também foi relevante por reduzir as populações de pragas monófagas, embora o mesmo não tenha ocorrido com as polífagas.

Outros trabalhos comprovam a importância do consórcio na elevação e manutenção das populações de inimigos naturais incidentes nas culturas. ROMERO et al. (1984) verificaram maior porcentagem de parasitismo em ovos de Empoasca kraemeri (Ross \& Moore) (Homoptera: Cicadellidae) por Anagrus sp. (Hymenoptera: Mymaridae) no cultivo do feijão consorciado com o milho que no cultivo exclusivo. PERFECTO et al. (1986) verificaram que besouros carabídeos predadores emigraram mais rapidamente de monocultivos de tomate ou feijão, que de sistemas consorciados com as duas culturas.

Apesar de muitos trabalhos já terem sido feitos para estudar os efeitos de policultivos sobre populações de pragas e seus inimigos naturais, os relativos ao consórcio feijão-milho da Zona da Mata Mineira ainda são pouco conhecidos, não obstante a relevância que tal sistema de cultivo representa para aquela região. Assim, o trabalho objetivou avaliar a ocorrência de insetos fitófagos e de predadores no milho e no feijão cultivados em sistema exclusivo e em associação.

\section{MATERIAL E MÉTODOS}

Este trabalho foi conduzido na Estação Experimental da Universidade Federal de Viçosa, Coimbra, MG, no ano agrícola 1996/97. A parcela experimental foi constituída de oito fileiras de oito metros, totalizando $64 \mathrm{~m}^{2}$ parcela ${ }^{-1}$. O experimento foi conduzido em blocos casualizados com quatro repetições. Os tratamentos foram representados por um fatorial de 2 (sistemas de cultivo: exclusivo e consorciado com feijão) x 2 (estadios fenológicos: fase vegetativa e reprodutiva) no caso do milho e 2 (sistemas de cultivo: exclusivo e consorciado com milho) x 3 (estadios fenológicos: pré-floração, formação e enchimento de vagens) no caso do feijão, sendo ambas culturas submetidas à adubação de $500 \mathrm{~kg}$ de 4-14-8 ha ${ }^{-1}$ no plantio e $200 \mathrm{~kg}$ de sulfato de amônio $\mathrm{x}$ ha $^{-1}$ em cobertura.

O espaçamento foi de $1,0 \times 0,2 \mathrm{~m}$ para o milho exclusivo e consorciado, resultando em população de 50.000 plantas ha-1. Para o feijoeiro consorciado com o milho nos cultivos "das águas" e "da seca", foram utilizadas populações de 150.000 e 300.000 plantas ha $^{-1}$, respectivamente. Tanto nas águas quanto na seca, o feijão solteiro foi plantado em densidade populacional de cerca de 300.000 plantas ha $^{-1}$.

O plantio do milho híbrido duplo C-435 de grão semiduro amarelo alaranjado, de ciclo precoce, foi realizado em 25/10/96. O plantio do feijão "das águas" foi realizado na mesma data do milho. O feijão "da seca" foi plantado em 20/01/97, após o milho ter atingido a maturação fisiológica. O cultivar utilizado em ambos os plantios foi o Meia Noite do grupo preto, de hábito de crescimento tipo II (indeterminado) e ciclo de 90 dias.

Foram realizadas avaliações das populações das pragas e predadores do milho aos 42 e 56 dias após o plantio, por contagem direta dos indivíduos presentes em 10 plantas, previamente casualizadas, na parte central das parcelas. O mesmo foi feito no feijão "da 
seca” e feijão “das águas”, aos 41, 55 e 73 dias após o plantio destas culturas. Os insetos foram avaliados tanto no cultivo exclusivo quanto no consorciado, sendo que, no cultivo consorciado, ambas as culturas foram avaliadas. Durante as avaliações, o milho se encontrava nas fases vegetativa e reprodutiva, já no cultivo do feijão, as plantas se encontravam nas fases de pré-floração, formação e enchimento de vagens.

Os resultados foram submetidos ao teste de Cochran para verificação da homogeneidade de variância dos dados e, quando necessário, foram transformados para $\sqrt{ }(x+0,5)$. Efetuou-se análise de variância comparando-se as médias pelo teste Tukey a $5 \%$ de probabilidade de erro.

Partindo-se das densidades populacionais dos insetos-praga e dos inimigos naturais incidentes no milho, feijão "das águas" e feijão "da seca", obtevese o número total de herbívoros e predadores/ unidade experimental. Após este procedimento, realizou-se a soma das densidades populacionais dos herbívoros e predadores presentes em uma mesma unidade experimental das diferentes fases de crescimento da cultura, obtendo-se médias referentes a quatro repetições. As médias foram então comparadas pelo teste $\mathrm{t}$ a $5 \%$ de probabilidade de erro.

\section{RESULTADOS E DISCUSSÃO}

Houve maiores intensidades de ataque de Dalbulus maidis e $\boldsymbol{S}$. frugiperda respectivamente na fase reprodutiva e fase vegetativa do milho exclusivo que no consorciado com o feijoeiro. $\mathrm{O}$ inverso foi verificado em relação às intensidades de ataque de Colaspis joliveti e $\boldsymbol{S}$. frugiperda no milho em fase reprodutiva. Maiores densidades populacionais dos Hymenoptera: Formicidae predadores foram encontradas no cultivo do milho exclusivo (cultura em fase reprodutiva) que no consorciado com o feijoeiro (Tabela 1).

As maiores intensidades de ataque de $\boldsymbol{D}$. maidis (cultura em cultivo exclusivo), de $\boldsymbol{C}$. joliveti $\mathrm{e}$ S. frugiperda (cultura em cultivo consorciado) ocorreram na fase reprodutiva do milho. Porém ocorreu maior intensidade de ataque de $\boldsymbol{S}$. frugiperda ao milho (cultura em cultivo exclusivo) em fase vegetativa (Tabela 1). Os predadores Geocoris sp. (cultura em cultivo consorciado) e Hymenoptera: Formicidae (cultura em cultivo exclusivo) apresentaram maiores densidades populacionais na cultura do milho em fase reprodutiva (Tabela 1).

Verificou-se que, no feijão "das águas", ocorreu maior intensidade de ataque de Diabrotica speciosa no cultivo exclusivo (cultura em estádio de pré-floração e formação de vagens) que no cultivo consorciado. $\mathrm{O}$ inverso ocorreu com as intensidades de ataque de Empoasca kraemeri e Thrips tabaci (cultura em estádio de formação de vagens) e Pseudoplusia includens (cultura em estádio de enchimento de vagens). As densidades populacionais dos predadores Anthicus sp. (cultura em estádio de pré-floração) e Hymenoptera: Formicidae (cultura em estádio de enchimento de vagens) foram maiores no feijoeiro em cultivo exclusivo que na mesma cultura consorciada com milho. O inverso foi verificado em relação às densidades populacionais dos predadores Hymenoptera: Formicidae (cultura em estádio de formação de vagens) (Tabela 1).

As maiores intensidades de ataque de Cerotoma arcuata (cultura em ambos sistemas de cultivo) e $\boldsymbol{P}$. includens (cultura em cultivo exclusivo) ocorreram no feijoeiro em estádio de enchimento de vagens. As intensidades de ataque de $\boldsymbol{T}$. tabaci e $\boldsymbol{E}$. kraemeri (cultura em cultivo consorciado) e de $\boldsymbol{D}$. speciosa (cultura em cultivo exclusivo) foram mais elevadas no feijoeiro em estádio de formação de vagens. Já no feijoeiro em cultivo exclusivo, as maiores densidades de E. kraemeri e do predador Anthicus sp. ocorreram quando a cultura estava em estádio de pré-floração (Tabela 1).

Observou-se que, no feijão "da seca", cultivado exclusivamente ocorreram maiores densidades populacionais de $\boldsymbol{C}$. arcuata (cultura em estádio de formação de vagens), $\boldsymbol{E}$. kraemeri (em todo o cultivo) e Hymenoptera: Formicidae (cultura em estádio de pré-floração) que no cultivo consorciado. $\mathrm{O}$ inverso foi verificado em relação à intensidade de ataque de $\boldsymbol{D}$. maidis (cultura em estádio de enchimento de vagens) (Tabela 2 ).

Verificou-se maior intensidade de ataque de D. maidis ao feijoeiro no estádio de enchimento de vagens (cultivo consorciado). Já $\boldsymbol{E}$. kraemeri concentrou seu ataque nos estádios de formação e enchimento de vagens (cultivo exclusivo). Os predadores Hymenoptera: Formicidae apresentaram maiores densidades populacionais no estádio de préfloração do feijoeiro (Tabela 2).

Não se detectou efeito significativo dos sistemas de cultivo sobre as densidades populacionais totais de herbívoros e predadores do milho. O mesmo foi constatado em relação às densidades populacionais totais de predadores incidentes no cultivo de feijão “das águas" (Tabela 2).

Maior incidência de herbívoros foi verificada no feijão "das águas" consorciado com o milho. O inverso ocorreu com as densidades populacionais totais de herbívoros e de predadores no feijão "da seca" (Tabela 2). 
Tabela 1 - Densidades médias ( \pm erro padrão) de Dalbulus maidis, Colaspis joliveti, Spodoptera frugiperda, Geocoris sp. e Hymenoptera: Formicidae na cultura do milho e de Cerotoma arcuata, Diabrotica speciosa, Empoasca kraemeri, Pseudoplusia includens, Thrips tabaci, Anthicus sp. e Hymenoptera: Formicidae na cultura do feijão "das águas", em função da fase das plantas e sistema de cultivo. Coimbra, MG. 1996/7.

\begin{tabular}{|c|c|c|c|c|}
\hline Fase das Plantas & Milho & Milho com Feijão & Milho & Milho com Feijão \\
\hline & \multicolumn{2}{|c|}{ (Dalbulus maidis/ 10 plantas $^{1 /}$ ) } & \multicolumn{2}{|c|}{ (Colaspis joliveti/ 10 plantas ${ }^{1 /}$ ) } \\
\hline Vegetativa & $5,00 \pm 2,89 \mathrm{aB}$ & $5,00 \pm 2,89 \mathrm{aA}$ & $155,00 \pm 34,28 \mathrm{aA}$ & $177,50 \pm 42,70 \mathrm{aB}$ \\
\hline \multirow[t]{2}{*}{ Reprodutiva } & $55,00 \pm 13,23 \mathrm{aA}$ & $15,00 \pm 8,66 \mathrm{bA}$ & $67,50 \pm 14,93 \mathrm{bA}$ & $337,50 \pm 29,83 \mathrm{aA}$ \\
\hline & \multicolumn{2}{|c|}{ (Spodoptera frugiperda/ 10 plantas $^{1 /}$ ) } & \multicolumn{2}{|c|}{$\left(\right.$ Geocoris $\mathrm{sp} . / 10$ plantas $\left.^{1 / 1}\right)$} \\
\hline Vegetativa & $62,50 \pm 13,15 \mathrm{aA}$ & $7,5 \pm 4,79 \mathrm{bB}$ & $2,50 \pm 2,50 \mathrm{aA}$ & $0,00 \pm 0,00 \mathrm{aB}$ \\
\hline \multirow[t]{2}{*}{ Reprodutiva } & $17,50 \pm 7,50 \mathrm{bB}$ & $70,00 \pm 12,91 \mathrm{aA}$ & $5,00 \pm 2,89 \mathrm{aA}$ & $7,50 \pm 2,50 \mathrm{aA}$ \\
\hline & \multicolumn{2}{|c|}{ (Hymenoptera: Formicidae/ 10 plantas $^{1 /}$ ) } & & \\
\hline Vegetativa & $5,00 \pm 2,89 \mathrm{aB}$ & $0,00 \pm 0,00 \mathrm{aA}$ & & \\
\hline \multirow[t]{3}{*}{ Reprodutiva } & $27,50 \pm 8,54 \mathrm{aA}$ & $0,00 \pm 0,00 \mathrm{bA}$ & & \\
\hline & Feijão & Feijão com Milho & Feijão & Feijão com Milho \\
\hline & \multicolumn{2}{|c|}{$\left(\right.$ Cerotoma arcuata/ 10 plantas $\left.^{1 /}\right)$} & \multicolumn{2}{|c|}{$\left(\right.$ Diabrotica speciosa/ 10 plantas $\left.^{1 /}\right)$} \\
\hline Pré-floração & $5,00 \pm 5,00 \mathrm{aB}$ & $2,50 \pm 2,50 \mathrm{aB}$ & $7,50 \pm 4,79 \mathrm{aAB}$ & $0,00 \pm 0,00 \mathrm{bA}$ \\
\hline Formação de vagens & $2,50 \pm 2,50 \mathrm{aB}$ & $2,50 \pm 2,50 \mathrm{aB}$ & $10,00 \pm 4,08 \mathrm{aA}$ & $0,00 \pm 0,00 \mathrm{bA}$ \\
\hline \multirow[t]{2}{*}{ Enchimento de vagens } & $35,00 \pm 11,90 \mathrm{aA}$ & $25,00 \pm 2,89 \mathrm{aA}$ & $0,00 \pm 0,00 \mathrm{aB}$ & $0,00 \pm 0,00 \mathrm{aA}$ \\
\hline & \multicolumn{2}{|c|}{$\left(\right.$ Empoasca kraemeri/ 10 plantas $\left.^{1 / 1}\right)$} & \multicolumn{2}{|c|}{ (Pseudoplusia includens/10 plantas $\left.^{1 /}\right)$} \\
\hline Pré-floração & $102,50 \pm 14,93 \mathrm{aA}$ & $57,50 \pm 28,69 \mathrm{aAB}$ & $0,71 \pm 0,71 \mathrm{aA}$ & $0,04 \pm 0,04 \mathrm{aB}$ \\
\hline Formação de vagens & $40,00 \pm 7,07 \mathrm{bB}$ & $97,50 \pm 20,16 \mathrm{aA}$ & $0,04 \pm 0,04 \mathrm{aA}$ & $1,35 \pm 1,35 \mathrm{aB}$ \\
\hline \multirow[t]{2}{*}{ Enchimento de vagens } & $5,00 \pm 2,89 \mathrm{aB}$ & $22,50 \pm 6,29 \mathrm{aB}$ & $2,16 \pm 1,25 \mathrm{bA}$ & $13,76 \pm 6,88$ aA \\
\hline & \multicolumn{2}{|c|}{$\left(\right.$ Thrips tabaci/ 10 plantas $\left.^{1 /}\right)$} & \multicolumn{2}{|c|}{ (Anthicus sp./ 10 plantas $\left.^{1 /}\right)$} \\
\hline Pré-floração & $7,50 \pm 4,79 \mathrm{aA}$ & $2,50 \pm 2,50 \mathrm{aB}$ & $15,00 \pm 2,89 \mathrm{aA}$ & $0,00 \pm 0,00 \mathrm{bA}$ \\
\hline Formação de vagens & $0,00 \pm 0,00 \mathrm{bA}$ & $260,00 \pm 100,25 \mathrm{aA}$ & $0,00 \pm 0,00 \mathrm{aB}$ & $0,00 \pm 0,00 \mathrm{aA}$ \\
\hline Enchimento de vagens & $0,00 \pm 0,00 \mathrm{aA}$ & $0,00 \pm 0,00 \mathrm{aB}$ & $0,00 \pm 0,00 \mathrm{aB}$ & $0,00 \pm 0,00 \mathrm{aA}$ \\
\hline \multicolumn{5}{|c|}{ (Hymenoptera: Formicidae/ 10 plantas $^{1 /}$ ) } \\
\hline Pré-floração & $15,00 \pm 5,00 \mathrm{aA}$ & $10,00 \pm 5,77 \mathrm{aA}$ & & \\
\hline Formação de vagens & $0,00 \pm 0,00 \mathrm{bA}$ & $17,50 \pm 8,54 \mathrm{aA}$ & & \\
\hline Enchimento de vagens & $12,50 \pm 4,79 \mathrm{aA}$ & $0,00 \pm 0,00 \mathrm{bA}$ & & \\
\hline
\end{tabular}

${ }^{1 /}$ Médias não seguidas pela mesma letra minúscula na linha ou maiúscula na coluna diferem, entre si, pelo teste de Tukey a 5\% de probabilidade de erro.

Menores densidades populacionais de herbívoros considerados preferenciais da cultura do milho (como D. maidis e $\boldsymbol{S}$. frugiperda) e do feijão (como D. speciosa, C. arcuata e E. kraemeri) estiveram associadas ao cultivo consorciado.

A teoria da estabilidade-diversidade sugere que quanto maior for a diversidade biológica de organismos de uma comunidade, maior é a sua estabilidade (ANDOW, 1991). Assim, cultivos consorciados podem ser considerados mais estáveis, o que pode resultar na redução da ocorrência de algumas pragas nesta situação. Segundo TAHVANAINEN \& ROOT (1972), alguns insetos-praga apresentam menores populações associadas a policultivos do que a monocultivos devido à maior diversidade destes agroecossistemas, o que dificulta a localização do hospedeiro pelo inseto praga, além de levar a alterações no microclima e interferir na dispersão dos insetos. Portanto, tais efeitos podem justificar a redução da incidência de tais herbívoros nas culturas em associação. Entretanto outros fatores como as fileiras de feijão ou de milho, agindo como barreira física para o movimento das pragas de uma fileira para outra, podem ter contribuído para a redução da infestação destes insetos no sistema consorciado (NATARAJAN \& NAIK, 1992).

Alguns herbívoros, mesmo sendo considerados preferenciais, (como $\boldsymbol{S}$. frugiperda e $\boldsymbol{E}$. kraemeri) foram mais abundantes no consórcio em algumas situações. A larva desenvolvida da lagarta do cartucho pode muitas vezes, especialmente quando o milho é precoce, dirigir-se para a região da espiga atacando o pedúnculo e impedindo a formação de grãos (MATRANGOLO et al., 1997). Neste período de migração, normalmente a lagarta fica mais exposta à ação de inimigos naturais. Assim, o sistema consorciado pode ter conferido maior proteção à praga da ação de agentes de controle biológico, contribuindo para ocorrência de maior densidade populacional do inseto neste cultivo e quando o milho se encontrava 
Tabela 2 - Densidades (média \pm erro padrão) de Cerotoma arcuata, Dalbulus maidis, Empoasca kraemeri e Hymenoptera: Formicidae na cultura do feijão "da seca" em função do estádio das plantas e sistema de cultivo e total de herbívoros e predadores (média \pm erro padrão) em função do sistema de cultivo do milho, feijão "das águas" e feijão "da seca". Coimbra, MG. 1996/7.

\begin{tabular}{|c|c|c|c|c|}
\hline Estádio das Plantas & Feijão & Feijão com Milho & Feijão & Feijão com Milho \\
\hline & \multicolumn{2}{|c|}{ (Cerotoma arcuata/ 10 plantas ${ }^{1 /}$ ) } & \multicolumn{2}{|c|}{ (Dalbulus maidis/ 10 plantas ${ }^{1 /}$ ) } \\
\hline Pré-floração & $10,00 \pm 5,77 \mathrm{aA}$ & $5,00 \pm 5,00 \mathrm{aA}$ & $0,00 \pm 0,00 \mathrm{aA}$ & $0,00 \pm 0,00 \mathrm{aC}$ \\
\hline Formação de vagens & $25,00 \pm 13,23 \mathrm{aA}$ & $5,00 \pm 2,89 \mathrm{bA}$ & $15,00 \pm 5,00 \mathrm{aA}$ & $27,50 \pm 10,31 \mathrm{aB}$ \\
\hline \multirow[t]{2}{*}{ Enchimento de vagens } & $25,00 \pm 9,57 \mathrm{aA}$ & $7,50 \pm 4,79 \mathrm{aA}$ & $7,50 \pm 4,79 \mathrm{bA}$ & $55,00 \pm 5,00 \mathrm{aA}$ \\
\hline & \multicolumn{2}{|c|}{$\left(\right.$ Empoasca kraemeri/ 10 plantas $\left.^{1 /}\right)$} & \multicolumn{2}{|c|}{ (Hymenoptera: Formicidae/ 10 plantas $^{1 /}$ ) } \\
\hline Pré-floração & $27,50 \pm 14,36 \mathrm{aB}$ & $0,00 \pm 0,00 \mathrm{bA}$ & $167,50 \pm 35,68 \mathrm{aA}$ & $70,00 \pm 14,72 \mathrm{bA}$ \\
\hline Formação de vagens & $240,00 \pm 77,57 \mathrm{aA}$ & $27,50 \pm 15,48 \mathrm{bA}$ & $47,50 \pm 11,09 \mathrm{aB}$ & $20,00 \pm 9,13 \mathrm{aAB}$ \\
\hline Enchimento de vagens & $182,50 \pm 36,60 \mathrm{aA}$ & $70,00 \pm 17,79 \mathrm{bA}$ & $17,50 \pm 8,54 \mathrm{aB}$ & $10,00 \pm 7,07 \mathrm{aB}$ \\
\hline \multirow[t]{2}{*}{ Grupo de insetos } & \multicolumn{4}{|c|}{ Insetos/ 10 plantas $^{2 /}$} \\
\hline & \multicolumn{2}{|c|}{ Milho } & \multicolumn{2}{|c|}{ Milho com Feijão } \\
\hline Herbívoros & \multicolumn{2}{|c|}{$265,00 \pm 40,52 \mathrm{a}$} & \multicolumn{2}{|c|}{$222,50 \pm 50,89 \mathrm{a}$} \\
\hline Predadores & \multicolumn{2}{|c|}{$85,00 \pm 39,48 \mathrm{a}$} & \multicolumn{2}{|c|}{$20,00 \pm 7,07 \mathrm{a}$} \\
\hline & \multirow{2}{*}{\multicolumn{2}{|c|}{$\begin{array}{l}\text { Feijão "das águas" } \\
222,50+34,25 \text { b }\end{array}$}} & Feijão "das & com Milho \\
\hline Herbívoros & & & \multicolumn{2}{|c|}{$\begin{array}{c}\text { Feijão "das águas" com Milho } \\
495,00 \pm 96,39 \mathrm{a}\end{array}$} \\
\hline Predadores & \multicolumn{2}{|c|}{$42,50 \pm 7,5 \mathrm{a}$} & \multicolumn{2}{|c|}{$\begin{array}{c}495,00 \pm 96,39 \mathrm{a} \\
27,50 \pm 13,77 \mathrm{a}\end{array}$} \\
\hline & \multicolumn{2}{|c|}{ Feijão "da seca" } & \multicolumn{2}{|c|}{ Feijão "da seca" com Milho } \\
\hline Herbívoros & \multicolumn{2}{|c|}{$330,00 \pm 71,88 \mathrm{a}$} & \multicolumn{2}{|c|}{$77,50 \pm 10,31 \mathrm{~b}$} \\
\hline Predadores & \multicolumn{2}{|c|}{$267,50 \pm 57,93 \mathrm{a}$} & \multicolumn{2}{|c|}{$135,00 \pm 17,08 \mathrm{~b}$} \\
\hline
\end{tabular}

${ }^{1 /}$ Médias não seguidas pela mesma letra minúscula na linha ou maiúscula na coluna diferem, entre si, pelo teste de Tukey a $5 \%$ de probabilidade de erro.

${ }^{2 /}$ Médias não seguidas pela mesma letra na linha diferem, entre si, pelo teste t $5 \%$ de probabilidade de erro.

em fase avançada de seu desenvolvimento (fase reprodutiva). Por sua vez, a maior incidência de lagartas na fase vegetativa das plântulas de milho se deu no monocultivo, possivelmente devido ao ataque da lagarta nesta fase tender a se concentrar no cartucho, naturalmente já protegido da ação destes possíveis agentes de controle biológico. Muitos insetos, apesar de serem considerados pragas preferenciais de certas culturas, podem, eventualmente, atacar a outra cultura em associação devido ao fato de a associação freqüente das culturas proporcionar adaptação dos principais grupos de insetos-praga à utilização de ambos recursos alimentares, tornando-se menos sujeitos a sazonalidade destes (PEDIGO, 1989). Assim, o fato de o feijão já se encontrar em fase adiantada de seu estádio de desenvolvimento (próximo à senescência), quando a manutenção da alimentação seria impedida em pouco tempo pelo final do ciclo da cultura, pode ter contribuído para a elevação da densidade de $\boldsymbol{E}$. kraemeri no consórcio no qual existia o milho, de maior longevidade que o feijão, como alternativa à alimentação dos insetos.

Em alguns tipos de consorciação, uma das culturas pode atuar como cultura armadilha. Essa pode ser uma possível explicação para a maior abundância de $\boldsymbol{C}$.joliveti no milho consorciado, ou seja, a presença do feijão no consórcio com o milho estaria agindo como cultura-armadilha para este inseto. Similarmente, a maior incidência de $\boldsymbol{D}$. maidis no feijão consorciado pode indicar que a presença do milho no consórcio com o feijão estaria agindo como cultura-armadilha para $\boldsymbol{D}$. maidis já que este inseto ataca preferencialmente $o$ milho.

No caso de $\boldsymbol{T}$. tabaci e $\boldsymbol{P}$. includens apesar de serem considerados insetos capazes de se alimentar em uma ampla faixa de hospedeiros, não são comumente encontrados ocasionando danos em plantas de milho, podendo, porém, serem encontrados atacando o feijoeiro. Como estes insetos foram mais abundantes no feijão consorciado com o milho, pode ser que o consórcio, neste caso, estivesse contribuindo para oferecer maior proteção aos insetos contra a ação de inimigos naturais e intempéries (como dessecação pelo vento e efeito deletério por altas temperaturas) (ANDOW, 1991).

Pela diversidade de resultados demonstrada acima e pela análise do comportamento geral adotado pelos herbívoros frente ao cultivo consorciado ou exclusivo das culturas (Tabela 2), percebe-se que não houve uma tendência única comportamental em função dos sistemas de cultivo.

Segundo SCHOONHOVEN et al. (1998), herbívoros que chegam a um agroecossistema usam, para localizar seu hospedeiro, estímulos visuais e/ou químicos. Em situação de policultivos em que existe ampla diversidade de estímulos, estes podem misturar- 
se uns aos outros atuando no confundimento dos herbívoros que estão emigrando para este ambiente (ANDOW, 1991). Observando-se o comportamento geral adotado pelos herbívoros no cultivo do feijão "das águas" e "da seca" pode se ter um indício de que tal fato tenha influenciado o comportamento dos insetos. Isso porque no cultivo "da seca", o feijão foi plantado quando o milho já se encontrava no estádio de maturação fisiológica, com as plantas tornando-se secas em pouco tempo. Assim, esse fato pode ter contribuído para dificultar a localização visual das plantas de feijão pelos herbívoros, já que dentre aqueles mais abundantes estavam as cigarrinhas $\boldsymbol{E}$. kraemeri (Tabela 2) as quais são muito atraídas pelo amarelo (LARA, 1991). Nesse contexto, a radiação refletida pelas plantas de milho (palhosas) se juntaria àquelas refletidas pelas plantas de feijão contribuindo para o confundimento dos herbívoros que chegassem a esse sistema à procura de seu hospedeiro, podendo resultar na emigração dos insetos. Já no plantio “das águas" o milho ainda se encontrava em plena atividade fisiológica quando da emergência do feijão (já que ambas as culturas foram plantadas simultaneamente). Nesse caso, ao invés de promover o confundimento dos herbívoros que imigravam para o sistema em que as duas culturas se encontravam associadas, o consórcio traria a vantagem adicional em relação ao monocultivo de possibilitar abrigo e, em alguns casos, diversidade de alimento (ANDOW, 1991) aos herbívoros incidentes neste sistema de cultivo.

Houve maior incidência dos predadores Hymenoptera: Formicidae no feijão "das águas" consorciado com o milho, o que concorda com a hipótese de que inimigos naturais são mais abundantes em policultivos, devido a maior diversidade de herbívoros normalmente presentes nestes cultivos, além de outras fontes alimentares como néctar e pólen e melhores condições de abrigo, microclima, dispersão e reprodução (ANDOW, 1991).

Porém a grande maioria dos inimigos naturais tendeu a ser mais abundante no monocultivo do que no consórcio, o que também foi explicitado pela análise das tendências gerais (Tabela 2). Como a densidade populacional dos inimigos naturais é dependente das densidades das pragas incidentes nas culturas, pode ser que outros fatores que não apenas o sistema de cultivo estivesse influenciando a densidade dos inimigos naturais no sistema. Como exemplo de tais fatores, pode-se citar a presença ou não de presas em densidades satisfatórias para a alimentação dos inimigos naturais. Neste contexto, QUINDERÉ \& SANTOS (1986) verificaram que, no milho consorciado com caupi o ataque de $\boldsymbol{S}$. frugiperda não atingiu o nível de controle, devido a himenópteros, dípteros e coleópteros predadores e ao parasitóide de ovos Chelonus sp. (Hymenoptera: Braconidae). Assim, devido ao fato de maior proporção de herbívoros ter sido associada ao cultivo exclusivo e considerando a natureza densidade dependente das populações de inimigos naturais, talvez isso explique o fato da maior densidade de inimigos naturais também ter sido associada ao cultivo exclusivo.

Tanto no milho quanto no feijão o ataque da maioria dos insetos-praga tendeu a se concentrar nas fases finais do ciclo das culturas. Ao iniciar-se o aparecimento das estruturas reprodutivas, reservas acumuladas nos tecidos vegetais começam a ser quebradas para serem enviadas aos órgãos reprodutivos (TAIZ \& ZEIGER, 1991). Esta remobilização geralmente é feita por meio de compostos simples como açúcares de baixo peso molecular e aminoácidos (TAIZ \& ZEIGER, 1991), os quais, formam a base alimentar de grande parte dos insetos fitófagos, já que substâncias de estrutura complexa como celulose, hemicelulose e lignina geralmente reduzem a digestibilidade de tecidos das plantas por insetos que se alimentam das folhas (PHELAN et al., 1996). Assim, a maior disponibilidade de compostos prontamente utilizáveis na seiva das plantas nesta fase, pode ter contribuído para que o ataque dos insetos fosse concentrado nesta mesma época.

De maneira geral, os predadores incidentes no milho concentraram sua ocorrência na fase de maior ocorrência de pragas, dado sua relação densidadedependente com as pragas que lhes servem de presas. Porém o mesmo não ocorreu com o feijão "da seca", indicando que não só as relações densidadedependente entre presa e predador estavam influenciando a ocorrência destes inimigos naturais.

No caso do feijão das águas em monocultivo, a fase da cultura em que ocorreu maior densidade populacional de ambos predadores foi a de maior ocorrência da cigarrinha verde $\boldsymbol{E}$. kraemeri.

Os predadores do gênero Anthicus são microcoleópteros que, segundo MAES \& CHANDLER (1994), alimentam-se de ovos de Lepidoptera, larvas de primeiros ínstares e pupas de outros insetos. Dado o tamanho reduzido das ninfas de Empoasca, associado a um mesmo local de ocorrência dos predadores (proximidade de nichos), talvez isso explique a concordância de ocorrência destes insetos em uma mesma fase da cultura, já que estas ninfas poderiam servir como alimento adequado a estes predadores. $\mathrm{O}$ mesmo não pode ser dito quanto aos outros insetos que foram incidentes na cultura (como as vaquinhas C. arcuata e D. speciosa e a lagarta P. includens) uma 
vez que a fase suscetível de predação de uns se encontra em um nicho diferente daquele ocupado pelo predador (no solo no caso das vaquinhas) e mesmo os primeiros ínstares larvais das lagartas podem não ser suficientemente pequenos para permitir uma predação eficaz por estes insetos.

Segundo ITIOKA \& INOUE (1996) muitas espécies de formigas predadoras podem alterar seus hábitos de predação em relação a homópteros, passando a protegê-los a fim de obter os resíduos de alimentação ou "honeydew" eliminados por estes homópteros. Assim pode ser que a maior densidade destes insetos tenha coincidindo com a fase da cultura de maior ocorrência das cigarrinhas, pelo fato de uma associação mutualística similar a que foi descrita acima ter se desenvolvido entre ambos nesta condição, representando uma adaptação ecológica a estes predadores.

\section{CONCLUSÕES}

Menores densidades de herbívoros considerados preferenciais da cultura do milho(Dalbulus maidis e Spodoptera frugiperda) e do feijoeiro (Diabrotica speciosa, Cerotoma arcuata e Empoasca kraemeri) estão associadas ao cultivo consorciado.

As densidades de herbívoros generalistas como Thrips tabaci e Pseudoplusia includens são maiores no feijoeiro consorciado com o milho.

No cultivo "das águas", o total de insetos fitófagos é maior no feijoeiro consorciado com o milho que no feijoeiro em monocultivo, sendo que o inverso ocorre no cultivo "da seca".

Os predadores Anthicus sp. e Hymenoptera: Formicidae no milho e no feijoeiro consorciado são menos abundantes que nestas culturas em monocultivo.

\section{AGRADECIMENTOS}

À Fundação de Amparo a Pesquisa de Minas Gerais (FAPEMIG) pelo financiamento do projeto e ao CNPq pelas bolsas concedidas.

\section{REFERÊNCIAS BIBLIOGRÁFICAS}

AIYER, A.K.Y.N. Mixed cropping in India. Journal of Agricultural Science, London, v.19, n.4, p.439-453, 1949.

ANDOW, D.A. Vegetational diversity and arthropod population response. Annual Review of Entomology, Palo Alto, v.35, p.561-586, 1991

CASTRO, M.T.; PITRE, H.N.; MECKENSTOCK. D.H. Fall armyworm and neotropical cornstalk borer on sorghum and maize intercropped with legumes in Honduras. Turrialba, Coronado, v.44, n.2, p.77-86, 1994.
ITIOKA, T.; INOUE, T. Density-dependent ant attendance and its effects on the parasitism of a honeydew-producing scale insect, Ceroplastes rubens. Oecologia, Berlin, v.106, n.4, p.448-454, 1996.

KAREL, A.K. Effects of intercropping with maize on the incidence and damage caused by pod borers common beans. Environmental Entomology, Lanham, v.22, n.5, p.10761083,1993

LARA, F.M. Causas da resistência. In: LARA, F.M. (ed.). Princípios de resistência de plantas a insetos. São Paulo: Ícone, 1991, p.75-135.

MAES, J.M.; CHANDLER, D.S. Catálogo de los Meloidea (Coleoptera) de Nicaragua. Revista Nicaraguense de Entomologia, Leon, v.28, n.1, p.31-42, 1994

MATRANGOLO, W.J.R.; CRUZ, I.; DELLA LUCIA, T.M.C. Insetos fitófagos presentes em estilo-estigma e espigas de milho e avaliação de dano. Pesquisa Agropecuária Brasileira, Brasília, v.32, n.8, p.773-779, 1997.

NATARAJAN, M.; NAIK, D.M. Competitive effects of a short duration, bush type cowpea when intercropped with cotton in Zimbabwe. Experimental Agriculture, New York, v.28, n.4, p.409-416, 1992.

PEDIGO, L.P. Entomology and pest management. New York: MacMillan, 1989. 646p.

PERFECTO, I. et al. Effects of plant diversity and density on the emigration rate of two ground beetles, Harpalus pennsylvanicus and Evarthus soclalis (Coleoptera: Carabidae). Environmental Entomology, Lanham, v.15, n.5, p.10281031,1986

PHELAN, P.L.; NORRIS, K.H.; MASON, J.F. Soil-management history and host preference by Ostrinia nubilalis: evidence for plant mineral balance mediating insect-plant interactions. Environmental Entomology, Lanham, v.25, n.6, p.13291336, 1996

QUINDERÉ, M.A.W.; SANTOS, J.H.R.. Efeito da época relativa de plantio no consórcio milho x caupi sobre a presença de insetos úteis e o manejo econômico das pragas. Pesquisa Agropecuária Brasileira, Brasília, v.21, n.4, p.355-368, 1986.

ROMERO, J.C.H. et al. Efecto de la asociacion maiz-frijol sobre populaciones de insectos plagas, com enphasis en Empoasca kraemeri Ross e Moore. Agrociência, Concepción, v.57, n.1, p.25-35, 1984.

SCHOONHOVEN, L.M.; JERMY, T.; VAN LOON, J.J.A. Plant chemistry: endless variety. In: SCHOONHOVEN, L.M.; JERMY, T.; VAN LOON, J.J.A. (eds.). Insect-plant biology - from physiology to evolution. New York: Chapman \& Hall, 1998. p. 23-47.

TAHVANAINEN, J.O.; ROOT, R.B. The influence of vegetational diversity on the population ecology of a specialized herbivore, Phyllotreta crucifeare (Coleoptera: Chrysomelidae). Oecologia, Berlin, v.10, n.3, p.321-346, 1972.

TAIZ, L., ZEIGER, E. Plant physiology. Redwood City: Benjamin/Cummings, 1991. 593p.

VANDERMEER, J. The ecology of intercropping. New York: Cambridge, 1989. 247p. 